\title{
Durkheim, Mauss e a atualidade da escola sociológica francesa
}

PAULO HENRIQUE MARTINS JULIANA DE FARIAS PESSOA GUERRA

\section{Resumo}

A escola sociológica francesa tem importância amplamente reconhecida para o desenvolvimento da sociologia acadêmica e contemporânea, o que se deve às contribuições de $\mathrm{E}$. Durkheim e $\mathrm{M}$. Mauss em primeiro lugar, mas igualmente a autores como C. Lévi-Strauss, G. Gurvitch, P. Bourdieu, A. Caillé entre outros. Porém, há um dado curioso: apesar de sua fama, desconhecem-se as características próprias da escola sociológica francesa no universo da teoria sociológica contemporânea. Por desconhecerem suas características alguns autores buscam enquadrar a sociologia francesa dentro do paradigma dualista agência $x$ estrutura, de origem anglo-saxônico. Ora, tal identificação é um erro epistemológico e impede entender que a sociologia francesa parte de outro paradigma: a lógica "efervescente" durkheimiana de diferenciação social que se desenvolve pela sistematização das noções de representação, simbolismo e totalidade social. Uma chave importante para o desvendamento da escola francesa, sobretudo de sua atualização teórica no contexto de individualização social que presenciamos na experiência das modernidades, é a sistematização por Mauss dos estudos sobre o dom, da regra tripartite do dar, receber e retribuir.

Palavras-chave: Sociologia-França. Diferenciação Social. Dádiva.

\footnotetext{
"Universidade Federal de Pernambuco (UFPE), Recife, Pernambuco, Brasil.

${ }^{* *}$ Universidade Federal de Pernambuco (UFPE), Recife, Pernambuco, Brasil.
} 


\section{Durkheim, Mauss and the current French sociological thought}

\section{Abstract}

The importance of French sociological thought for the development of contemporary academic sociology is widely recognized, especially for the contributions of E. Durkheim and M. Mauss, but also of authors as C. Lévi-Strauss, G. Gurvitch, P. Bourdieu, A. Caillé, among others. There is, however, an interesting fact: in spite of its prestige, the particular characteristics of the French sociology are unknown in the world of contemporary sociological theory. And, for being unaware of its characteristics, some authors try to define the French sociology within the British dualistic paradigm agency versus structure. Now, such demarcation constitutes an epistemological mistake that prevents the understanding that French sociology draws on another paradigm: the "effervescent" Durkheimian logic of social differentiation that is developed through the systematization of the notions of representation, symbolism and social totality. An important key for disclosing the French sociological thought, particularly its new theoretical formulation in the context of social individualization observed in modernity, is Mauss' systematization of studies on the gift, of the three obligations: to give, to receive and to reciprocate.

Keywords: French sociology. Social differentiation. Gift.

\section{Introdução: A escola sociológica francesa}

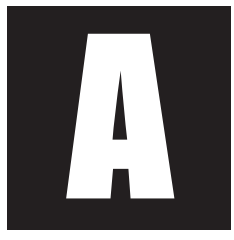

importância da escola sociológica francesa para o desenvolvimento da sociologia profissional é amplamente reconhecida e contribuíram para isto além de Durkheim autores como M. Mauss, C. Lévi-Strauss, G. Gurvitch, P. Bourdieu, A. Caillé e outros. Porém, apesar de sua fama, poucos identificam com clareza o status desta escola no universo da teoria sociológica contemporânea. De imediato, identificamos alguns problemas que explicam esta confusão. Uma deles tem relação com a leitura funcionalista da obra de Durkheim por T. Parsons, o que valorizou 
excessivamente a primeira tópica durkheimiana voltada para a importância da divisão do trabalho social (Durkheim, 2008), negligenciando-se a segunda tópica sobre as representações coletivas (Durkheim, 2009), e a terceira, sobre o diálogo com o pragmatismo (Durkheim, 2004). Tudo isto contribui para confundir o entendimento da valiosa contribuição da escola sociológica francesa para as ciências sociais, ontem e hoje.

Outro problema é a tentativa equivocada de situar o debate francês holismo $x$ individualismo dentro do paradigma agência x estrutura, que informa o desenvolvimento da sociologia anglo-saxônica, e que ganhou fama a partir do confronto entre os defensores do estruturalismo parsoniano e os das escolas interacionistas ${ }^{1}$. Ora, a sociologia francesa parte de outro paradigma, o de holismo x individualismo, que não reconhece a existência de uma dualidade ontológica primeira (agência x estrutura), mas que considera, diversamente, a existência de um continuum entre o todo e a parte - que aparece, secundariamente, em Durkheim como uma dualidade histórica entre holismo e individualismo. Um terceiro problema é a dificuldade de se entender o diálogo entre Durhheim e Mauss no desenvolvimento da escola e na passagem de uma visão positivista fundada na diferenciação para outra propriamente simbólica e fundada na integração do fato social num vasto simbolismo, que está presente na teorização sobre a dádiva.

Na verdade, é preciso esclarecer desde logo que o paradigma sociológico francês se inspira tanto na tradição positivista de A. Comte, que

\footnotetext{
${ }^{1} \mathrm{O}$ paradigma anglo-saxônico foi diretamente inspirado pela fenomenologia de A. Schutz (1972) e pela tradição pragmatista de J. Dewey (1991), C. Taylor (1998) e outros, ganhando notoriedade através de A. Giddens cuja teoria da estruturação permite um entendimento refinado das noções de agência e estrutura (Giddens, 1984). Mas o paradigma agência x estrutura tem data e lugar, e não pode ser generalizado como um marco interpretativo universal. Ele apenas pode prosperar dentro do universo do racionalismo empirista inglês que está mais próximo das teorias psicológicas do eu cognitivo e racional do que das representações simbólicas da pessoa, que vemos na escola francesa, ou das especulações sobre sujeito e ética, que vemos na escola alemã (Martins, 2012).
} 
elege a ordem social como momento decisivo para o desenvolvimento humano, como nas representações aristotélicas da natureza, que fundam a anterioridade do todo sobre as partes, como veremos com mais detalhes na seção seguinte. Exemplo deste raciocínio francês se encontra no texto de autoria de A. Caillé, intitulado Nem holismo, nem individualismo metodológico, Marcel Mauss e o paradigma da dádiva (Caillé, 1998), no qual o autor busca demonstrar que a dádiva constitui um paradigma relacional que inclui o todo (o sistema da dádiva formado por três movimentos conexos: dar, receber, retribuir) e as partes (cada um dos três movimentos vistos na singularidade) ${ }^{2}$. O fato é que nem o holismo (a totalidade) se reduz à estrutura, nem o individualismo (a particularidade) à agência, mas eles se articulam num movimento contínuo de diferenciação social ${ }^{3}$.

O debate francês se inspira sobre a tradicional questão de saber como ocorre o processo de diferenciação social nas sociedades industriais no contexto de organização das sociedades nacionais e das instituições republicanas como a escola, a família e as associações profissionais entre outros. No desenvolvimento deste debate francês prosperaram, com mui-

\footnotetext{
${ }^{2}$ A dádiva é, ao mesmo tempo, a totalidade social e suas partes instituintes, e as articulações entre as partes não segue uma lógica funcional mas, ao contrário, uma lógica paradoxal. Por essas e outras razões, torna-se necessário aprofundar o estudo desta escola, inclusive para ajudar na reorganização dos cursos de teoria sociológica que, pelo menos no caso brasileiro, ficam em geral limitados ao debate anglo-saxônico sobre agência e estrutura.

${ }^{3}$ As distinções não são somente semânticas, mas ontológicas. Assim, as categorias anglo-saxônicas de agência e estrutura são essencialmente distintas da lógica classificatória continental, o que reflete a tradição liberal inglesa de J. Locke, na qual a identidade individual sempre foi valorizada como um átomo social com características próprias e diversas da sociedade como um todo. E o debate sobre estrutura social desenvolvido por Parsons apenas radicalizou esta separação ontológica presente na tradição liberal inglesa entre a norma dos legisladores e a liberdade individualista. Ainda hoje, o debate anglo-saxônico inspira-se na intrigante questão lógica de saber como o voluntarismo individual, por um lado, e as normas sociais, por outro, interferem na ação social. A teoria da estruturação de A. Giddens (1984) reflete esta tensão a um limite máximo. No desenvolvimento deste debate anglo-saxônico, não há dúvidas de que a tese da racionalidade individual tem prosperado e se expandido como vemos pelo prestígio adquirido pela teoria do rational choice nos Estados Unidos, na atualidade.
} 
ta intensidade, preocupações contratuais, morais e jurídicas com a ordem e a desordem social ao longo da travessia de estruturas sociais mecânicas para outras orgânicas e diferenciadas. O tema do indivíduo se apresenta preferencialmente pelo conceito de individualismo moral, como vemos na obra de Durkheim (1997), não havendo sentido aqui de medir a racionalidade da agência, mas de situar a ação individual dentro de sistemas de prestações e obrigações mais amplas.

Considerando a diversidade de fatores a serem analisados para o desenvolvimento do texto, propomos como passos a serem seguidos os seguintes: a) Apresentação do pensamento classificatório de Durkheim, que é importante para se entender que o "clássico" francês se apoiava numa lógica de diferenciação social entre a totalidade e a particularidade que não tem relação com o pensamento empirista anglo-saxônico influenciado pelo liberalismo inglês; b) Demonstração da atualização do pensamento durkheimiano sobre a diferenciação social, a partir da importância de explicar a emergência da individualidade na sociedade moderna, o que o leva a dar passos importantes nos estudos sobre representação em Formas Elementares... e sobre verdade e individualidade, no debate com os pragmatistas norte-americanos; c) Reflexão sobre o diálogo entre Durkheim e Mauss no desenvolvimento da escola francesa, o que permite entender a complexidade da emergência do simbólico e do fato social total; pois a emergência do simbolismo entre Dukheim e Mauss tem impactos importantes sobre as ciências sociais, a semiologia, a linguística, o estruturalismo e, mais recentemente, o pós-estruturalismo; e) Análise da teoria da dádiva, que se constitui num momento importante do desenvolvimento da escola francesa sendo de grande atualidade para a crítica à moral capitalista do interesse e do lucro, no momento atual. 


\section{Durkheim: a efervescência social e o pensamento classificatório}

Durkheim recuperou a categoria aristotélica do entendimento humano (Aristóteles, 1995) para organizar sua lógica teórica plural e diferencial. Assim, noções como as de tempo, de espaço, de gênero, de causa, de substância, de personalidade entre outras são acionadas no esforço teórico de explicar que o grupo humano em fusão é o fundamento último da vida social, antes mesmo de qualquer representação classificatória. No entanto, para ele, o desenvolvimento do pensamento classificatório permitiu ao homem se afastar crescentemente da situação de efervescência inicial da comunidade, que seria algo caótico entre o estado da natureza e o estado da cultura, para situações de solidariedades contratuais mais complexas $^{4}$. Para ele, mesmo que se apresentem de forma diferente, as categorias do entendimento podem ser encontradas em qualquer sociedade, ao contrário das representações coletivas que variariam de uma sociedade para a outra. Tais categorias, entretanto, têm uma significação ambígua para Durkheim que oscilava entre entender as categorias como sendo, por um lado, construídas socialmente, e, por outro, como sendo fundadoras do conhecimento e da razão.

Dessa forma, tal pensamento emerge como o pensamento da ordem - o que não é estranho, quando entendemos que a escola francesa, no final do século XIX, inscrevia-se ainda, necessariamente, na tradição do positivismo comtiano. Mas, para Durkheim, a ordem do social não se submetia a uma força mecânica simples. Ao contrário, no esforço de liberar a força bruta, os seres humanos estruturam a ordem da classificação

${ }^{4} \mathrm{O}$ Estado, diz Aristóteles, tem, por natureza, maior importância do que a família e o indivíduo, uma vez que o conjunto é necessariamente maior que as partes. A prova de que o Estado é uma criação da natureza e tem prioridade sobre o indivíduo é que o indivíduo, quando isolado, não é autossuficiente; no entanto ele o é como parte relacionada do conjunto (Aristóteles, 1999, p. 146-147). 
mental das coisas gerando os fundamentos do conhecimento, ou seja, os sentimentos, as emoções, os valores e tudo aquilo que condiciona o pensamento ou representação sobre a vida humana. Diz ele sobre tais fatos:

(...) Eles são como quadros rígidos que encerram o pensamento; este não parece poder libertar-se deles sem se destruir, pois tudo indica que não podemos pensar objetos que não estejam no tempo ou no espaço, que não sejam numeráveis etc.. As outras noções são contingentes e móveis; concebemos que elas possam faltar a um homem, a uma sociedade, a uma época, enquanto aquelas nos parecem quase inseparáveis do funcionamento normal do espírito. São como a ossatura da inteligência (Durkheim, 2009, p. XVI).

As categorias aristotélicas são, pois, referências para Durkheim pensar a construção das representações coletivas e da ideia da sociedade como fato total. Já na Divisão do Trabalho Social (2008) e na descrição da passagem da solidariedade mecânica para a solidariedade orgânica, Durkheim demonstra o valor de seu pensamento classificatório para a superação de uma visão reducionista da realidade social e para o desenvolvimento de uma teoria do contrato social, que se funda em representações coletivas e simbólicas mais complexas sobre a natureza da consciência coletiva. A solidariedade mecânica vai perdendo espaço para a orgânica, na medida em que a sociedade evolui de uma estrutura holística para outra individualista. E a função moral da divisão social é o elemento chave para a integração dos indivíduos na sociedade. Dessa maneira, Durkheim entende que a verdadeira função da divisão do trabalho social é de servir como fator principal na geração do sentimento de solidariedade entre os indivíduos de determinada sociedade. Porém, com a crescente diversificação das funções, cresceria também o sentimento de individualidade entre os indivíduos e a consciência coletiva acabaria perdendo seu papel de modelador do social (Durkheim, 2008, p. 223), sendo necessário repensar a relação entre função e contratualidade. 
Dessa forma, as antinomias geradas pela separação entre realidade e representação, assim como aquelas de sociedade e indivíduo, de sagrado e profano ou de religião e magia, seriam fundamentais para se analisar a solidariedade social a partir do trabalho de reorganização da função pela imposição normativa da sociedade complexa. Por isso, o fato religioso passa a assumir, em As Formas elementares da Vida Religiosa (2009), uma dimensão constitutiva especial da realidade social. Pois, para o autor, era importante o desenvolvimento de uma teoria da solidariedade que não se limitasse ao contrato moral, mas que se impusesse como uma representação compartilhada por pessoas morais e individuais, e o simbolismo religioso foi a chave para esta saída teórica. Essa tensão teórica entre contrato e representação, que se desdobra em todas as dimensões da objetividade e da subjetividade, amplia-se, no nosso entender, na passagem de Formas elementares para Pragmatismo e sociologia, quando Durkheim é obrigado a refletir sobre que elementos podem assegurar vínculo social obrigatório em contextos de autonomização individual como aqueles próprios das sociedades industriais modernas.

Assim, as limitações teóricas desta visão dualista durkheimiana não tiram os méritos de Formas elementares, que se tornou uma obra emblemática das ciências sociais ao eleger a religião não como uma ficção tradicional, mas como um fenômeno simbólico, uma crença humana coletiva que impacta na produção das solidariedades entre pessoas (coletivas e individuais) na organização da vida social. Na categorização durkheimiana, a força coletiva se sobrepõe às consciências individuais, pois, tal como a sociedade, a religião só pode ser originária da criação coletiva ${ }^{5}$. Mas esta

\footnotetext{
${ }^{5} \mathrm{O}$ contrário acontece com a magia, segundo o autor, pois se trata de uma atividade que se desenrola em lugares marginais, praticada sempre por um indivíduo. Em As formas elementares (2009), a magia recebe um tratamento periférico por parte do autor, que toma o fenômeno religioso como expressão maior da vida coletiva. Esta leitura periférica se deve à dificuldade de Durkheim de superar a distinção entre realidade e representação, pois, para ele, as práticas mágicas só podem ser compreendidas como um contraponto dos fenômenos religiosos (Durkheim, 2009, p. 393).
} 
sobreposição não é uma atividade simples na medida em que a parte é peça fundamental para a existência da relação entre todo e parte. Isso the permite relacionar as crenças religiosas e cognitivas no interior de uma teoria geral das representações coletivas que não se fecha num sistema teórico holístico simples mas que se abre para as tensões dualistas fundadas nas representações pois, Os primeiros sistemas de representações que o homem produziu no mundo e de si próprio são de origem religiosa (Durkheim, 2009, p. XV).

Pode-se dizer que, com esta tese, Durkheim coloca a religião como um fenômeno sociológico passível de ser estudado cientificamente. Por isso, o sagrado e o profano seriam categorias que dificilmente se classificam na mesma unidade de tempo e de espaço. Em razão da barreira que separa o sagrado do profano, diz ele, o homem só pode entrar em contato intimo com as coisas sagradas se se despojar do que há de profano nele (Durkheim, 2009, p. 328). Por outro lado, sugere, podem-se manejar as coisas profanas, nas atitudes, nos gestos e nas linguagens, pois elas participam de algum modo da experiência religiosa. Diz ele, ainda, que o mundo que o sistema total dos conceitos exprime é aquele que a sociedade representa, somente a sociedade pode nos fornecer as noções segundo as quais ele deve ser representada (Durkheim, 2009, p. 491). Assim, a ação domina a vida religiosa pelo simples fato de a sociedade ser a sua fonte. Se a religião produziu o que há de essencial na sociedade, a ideia de sociedade é a alma da religião.

Para Durkheim, o simples relacionamento social entre os homens não é suficiente para constituir as categorias fundamentais do entendimento humano, devendo haver um grupo próprio que defina sua identidade a partir do compartilhamento de estruturas simbólicas e normativas. É, assim, a partir do entendimento da constituição do grupo social não como mera função mecânica, mas como ação organizada a partir de so- 
lidariedades consentidas socialmente entre grupos e indivíduos morais, que se desenvolve a noção de todo social durkheimiano. Esta noção nos ajuda a compreender que sua teoria do pensamento coletivo não é mera projeção da divisão funcional e histórica, mas ação incorporada moralmente e simbolicamente pela coletividade num contexto de individualização social. E, neste debate, o simbólico ganha força como campo de produção do conhecimento sobre a realidade, a partir das significações mutuamente compartilhadas:

As imagens genéricas que se formam em minha consciência pela fusão de imagens similares não representam senão os objetos que percebi diretamente. (...) Esta noção do todo, que está na base das classificações que apresentamos, não pode provir do indivíduo, que não é senão uma parte em relação ao todo e que não passa de uma fração ínfima da realidade. No entanto, talvez não haja categoria mais essencial do que esta, pois, como o papel das categorias é envolver todos os outros conceitos, a categoria por excelência parece dever ser exatamente, o conceito de totalidade (Durkheim, 2009, p. 490).

Como vemos, o desenvolvimento da lógica das categorias em Durkheim está fundado na hipótese de que a sociedade é uma categoria total que se realiza por subcategorias. Para que seja formada a primeira sociedade, é preciso que a força dos homens associados se transfira para essa primeira representação coletiva. Ao remeter à totalidade, esse símbolo coletivo do grupo é sacralizado por encarnar a maior das forças da natureza: a da associação dos homens. Assim, o fenômeno social apenas se completa quando é incorporado num símbolo (Durkhein, 2009).

Apesar dos avanços próprios deste entendimento, há que se notar, porém, que o simbólico na sua obra continua exterior à força dos homens. Mas, o que é a força se não o próprio ato de simbolização? Este passo, contudo, não foi dado por Durkheim, embora pareça que ele o buscava quando resolveu debater com os pragmatistas norte-americanos. Mas entender sua lógica binária é importante para se compreender a força do 
simbólico e da religião no desenvolvimento desta sociologia. O surgimento da terceira tópica de Durkheim, aquele do debate com o pragmatismo, nos parece decisivo para se entenderem os esforços deste autor para estabelecer diálogo com os pragmatistas e fenomenólogos norte-americanos que formulavam reflexões sobre a relação entre experiência individual e verdade, como veremos a seguir.

\section{Diálogo de Durkheim com os pragmatistas norte-americanos}

É curioso observar que, logo após a publicação de Formas Elementares, Durkheim organizou um curso sobre o pragmatismo, no qual ele aplica sua tese sobre representação e realidade a partir do confronto com as ideias do pragmatismo norte-americano sobre experiência individual e verdade, estando estas notas reunidas num livro intitulado Pragmatismo e Sociología (Durkheim, 2004). Dizem que ele teria sofrido muitas críticas por exagerar a importância da religião na organização da realidade social, o que faz certo sentido. Porém, não podemos esquecer que a localização da "parte" no "todo" foi tema que preocupou muito Durkheim, desde sempre.

O fato é que, no seu curso sobre pragmatismo na Sorbonne, entre dezembro de 1913 e maio de 1914, Durkheim buscou articular a ideia de verdade individual dos pragmatistas com a ideia de verdade na experiência do coletivo. A iniciativa de Durkheim nos ajuda a compreender o que estava em curso no interior da escola francesa naquele momento, a saber: um movimento de superação de uma visão holística simples de comunidade humana, pela qual as representações manifestariam os movimentos de grupos em fusão, para se aceitar a perspectiva da experiência direta dos indivíduos na busca pela verdade, ainda que dentro de certas condições de se pensar e se representar que remeteriam à totalidade social.

Neste curso, verifica-se o esforço de Durkheim de articular as representações coletivas com as experiências dos indivíduos em interação 
na vida cotidiana, abrindo diálogo com fenomenólogos pragmatistas norte-americanos como James, Peirce, Dewey e outros. Considerado por William James como um método para interpretar a verdade a partir de suas consequências práticas, o pragmatismo se afasta das abstrações, dos princípios fixos estabelecidos a priori, dos sistemas fechados e absolutos e volta-se para a concretude e adequação aos fatos, à ação (James, 1981). Destarte, a verdade seria uma característica das crenças, as quais nos ajudam a lidar com nossas experiências cotidianas ${ }^{6}$. No nosso entender, é aqui que Durkheim irá organizar sua polêmica, pois, ao explorar a relação entre verdade individual e crença, como vemos nas formulações de alguns pragmatistas, ele buscava defender a anterioridade da totalidade não como idealização, mas como condição objetiva de produção da verdade.

Considerando que o pragmatismo e os teóricos norte-americanos adotam uma abordagem fenomenológica que valoriza a presença do indivíduo na organização do mundo (que lhe é dado como verdade e crença), podemos entender que o interesse de Durkheim por esta escola significou uma importante busca de teorização do mundo das práticas, e que vai ser sistematizada posteriormente por autores como Mauss e Bourdieu. A relação intelectual de Durkheim com as teses pragmatistas pendia, portanto, entre ceticismo e curiosidade, pois reconhecia nelas, sobretudo nas teorias mais sociológicas de C. Peirce, G. Mead e W. James, um sentido de vida e de ação individual que seria muito importante para os estudos da sociedade ${ }^{7}$. Assim, a tese de James, de que se a crença é vivida como

\footnotetext{
${ }^{6}$ Ao discutir sobre a concepção dogmática da verdade, os pragmatistas recolocaram em questão o postulado do racionalismo e do empirismo clássico, afirmando que a concepção da ideia verdadeira é a representação mental das coisas, que corresponde ao objeto representado (Durkheim, 2004, p. 66).

${ }^{7}$ Nesta direção, Martins ratifica a importância desta aproximação dentro da visão classificatória de Durkheim e na busca de organizar teoricamente o lugar da experiência individual no seu sistema de totalidade ao propor que Penso que neste curso está, de fato, a chave que explica a sistematização por Mauss da dádiva. Pois, se por um lado, esta é concebida como um sistema geral de obrigações coletivas (reforçando a tese de Durkheim a respeito da sociedade como fato
} 
verdade ela é verdadeira, e que o monismo-pluralismo é uma questão de fundo para a filosofia moderna, exposta em seu livro Pragmatism, publicado originalmente em 1907 (James, 1981, p. 131), despertou muito o interesse do autor francês.

Por outro lado, a afirmação do mesmo James em Variedades da experiência religiosa, de 1902, de que a religiosidade é uma vivência extática individual válida socialmente, poderia em princípio parecer contrariar a afirmação de Durkheim sobre a precedência do conceito sobre a experiência, mas tal contrariedade é apenas aparente. Primeiramente, porque James, como Durkheim - e Mauss -, adota uma perspectiva plural com relação às determinações da vida cotidiana; em segundo lugar, porque a ideia de James da religião como uma significação produzida pela experiência lembra a metáfora da efervescência durkheimiana, que não é mera ficção, mas experiência coletiva tida como verdadeira na organização e classificação da vida social.

Nessa perspectiva, a iniciativa de Durkheim de se debruçar sobre as teses pragmáticas que valorizam a relação entre indivíduo e verdade pode ter sido fruto de seu esforço de buscar aliados para defender a atualidade de sua teoria positivista da classificação, que foi revista progressivamente pela introdução do simbolismo como fator produtor de solidariedades morais individuais e coletivas. Por conseguinte, nesta aproximação, ele revela seu interesse pelo valor da experiência individual na construção da ordem social, o que, para nós, é prova do surgimento desta terceira tópica do seu pensamento, a qual tem sido negligenciada por razões já apontadas neste artigo. Esta tópica, vale lembrar, abre brecha importante

moral), por outro, Mauss faz questão de adentrar o universo da experiência direta dos membros da sociedade, o que Ihe permite introduzir um elemento de incerteza estrutural na regra tripartite do dar-receber-retribuir, escapando da hiper-presença de uma obrigação coletiva que deveria se impor tiranicamente sobre a liberdade individual (Martins, 2006, p. 93). 
para o surgimento de uma teoria das prestações totais ancorada em regras de obrigações coletivas e individuais que tornam mais complexa a noção de totalidade social, e que vai ser sistematizada posteriormente por outros membros da escola, como Mauss e Lévi-Strauss.

Durkheim não permaneceu, logo, indiferente à tese de James acerca do conceito ser um produto da ação ou da experiência, mas tentou adaptá-la a seu marco interpretativo. Assim, na sua aula sobre a Ideia de Verdade, Durkheim defendeu a origem do processo de conhecimento como a ideia de algo a ser feito, e o que se encontra ao final desse processo é sempre uma ação (Durkheim, 2004: 124), o que o aproxima dos pragmatistas. Destarte, o papel da ideia verdadeira é muito menos nos encaminhar ao objeto como tal do que nos colocar em relação com ele. Como o próprio define:

A idéia, considerada na sua função, é um instrumento que nos permite lidar com o objeto em melhores condições. $O$ conhecimento não é senão um meio de entrar em relações frutíferas com a realidade, seja ou não a cópia dessa realidade uma dessas relações (Durkheim, 2004, p. 124).

Por outro lado, Durkheim endossou a crítica dos pragmatistas contra o racionalismo (que separa o pensamento da existência) e o empirismo (que não reconhece a razão como forma de experiência individual) ao longo de suas lições. Ele passou a aceitar a experiência como modalidade de organizar livremente o pensamento categorial, embora não tenha abandonado a ideia do grupo efervescente ligado organicamente por obrigações simbióticas, articulando esta liberdade dos agentes sociais.

Em Sociologia e Pragmatismo (2004), Durkheim faz uma revisão teórica do excessivo individualismo do pragmatismo, apontando como caminho a valorização do indivíduo no coletivo. Mas, num exercício de autocrítica, ele revê suas posições anteriores sobre a força do coletivo no surgimento das representações, atribuindo ao indivíduo um lugar como 
criador das categorias sociais. A categoria indivíduo - e não apenas o individualismo moral - é elevada a um status mais honroso na última fase de Durkheim. Inicialmente concebido de forma passiva, o indivíduo torna-se cada vez mais a origem de seu pensamento. E, opondo-se de modo ambivalente ao pragmatismo individualista de James, Durkheim caminhou em direção a uma concepção próxima do interacionismo simbólico de George Herbert Mead e do pragmatismo peirceano. Ele se aproximou do pragmatismo de Peirce, quando sustentou que a representação é obra coletiva, pois, diz, é o pensamento que cria o real, e o papel eminente das representações coletivas é o de 'realizar' essa realidade superior que é a própria sociedade (Durkheim, 2004, p. 188).

Nessas lições, Durkheim reforça a importância de enraizar os valores fundamentais do homem em sua experiência coletiva, sempre se colocando a seguinte questão: como atribuir certa primazia à representação simbólica da experiência do individuo no contexto de sua experiência e representação coletiva? O recurso ao "social" é a marca do seu sentimento das condições existenciais da escolha e que inclusive serve para delimitar seu campo de interpretação dualista entre a sociologia (do grupo) e a psicologia (do individual).

Durkheim reconhecia que toda moral implica em pelo menos um princípio - um julgamento de valor - que não tem origem na ciência, mas na realidade social e individual. Assim, caso queiramos saber o que é verdade, não podemos determinar a priori o que ela deve ser idealmente, mas sim temos de estudar as verdades reconhecidas como tais pelos homens em sociedade, e analisar suas características (Durkheim, 2004, p. 37$)^{8}$. Por isso, é justo se perguntar se, com este curso, estamos presenciando certa abertura de Durkheim para entender o símbolo ao mesmo

\footnotetext{
${ }^{8}$ Certamente, esta fase de Durkheim constituiu uma fonte de inspiração decisiva para Mauss fundir a representação no social, o coletivo no individual, o sagrado no profano, concebendo, enfim, a tese do fato social total.
} 
tempo como significado e significante que articula a verdade, a realidade e a crença entre o todo e a parte. Este questionamento nos leva a propor que estaria sendo aqui moldada a base do sistema da dádiva, permitindo articular representação e prática, (Martins, 2008).

Provavelmente todas as interrogações sobre esta terceira tópica e sobre o papel de Durkheim para a organização de uma teoria do fato social total que articula sincronicamente individuo e sociedade, verdade e representação, experiência e crença estavam contidas neste momento da produção da escola francesa. Ou seja, Durkheim tanto se preocupava em se defender daqueles que criticavam sua tese sobre a positividade das crenças, como igualmente estava interessado em demonstrar que sua teorização sobre crenças tinha relações diretas com a tese pragmatista de James (1981), segundo a qual o valor da ideia se justifica por seus desdobramentos práticos. Demonstrando a compatibilidade entre sua teoria do fato social com a fenomenologia pragmática, Durkheim anularia uma parte das críticas importantes à sua obra - e que tinha a ver com a questão de como situar o indivíduo moderno na sua tese da totalidade social - liberando uma construção sociológica rica e fundada na circularidade dos bens simbólicos e materiais que organizam os agentes individuais e coletivos como totalidade, como vamos verificar posteriormente com o sistema da dádiva.

Voltando ainda à discussão de Williams James sobre o fenômeno religioso como sendo baseado na experiência individual, podemos dizer que os pragmatistas prestaram uma enorme contribuição à sociologia francesa, ao demonstrarem que, no mundo do dia a dia, a experiência do sujeito não se baseia somente na obrigação, mas igualmente na liberdade. Num mundo crescentemente individualizado, as representações coletivas postulam um vínculo indissociável entre o pensamento e a vida, ou a existência espiritual e a humana. O primordial para James era a experiência, não o espírito ou as coisas, e, para ele, a verdade não seria independente da ação humana, nem um dado separado da vida. Explorando esta afir- 
mação, Durkheim lembrou, contudo, que o pensamento não se afirma somente a partir do objeto e que a existência deste como prática do entendimento apenas poderia nascer de um pensamento (social) que articulasse realidade e verdade. As consequências desse raciocínio na obra do sociólogo francês se refletiram numa articulação teórica mais estreita entre o sujeito e o objeto do pensamento no mundo:

Se o pensamento é uma cópia das coisas, não vemos como ele pode atingi-las, pois existe um abismo entre a mente e o objeto. (...) Só podemos atingir o objeto se pensarmos. Se for pensamento, ele nos é interior. É impossível, então, controlar a verdade da idéia. (...) seja qual for a forma que dermos à teoria da verdade, a questão que se coloca inevitavelmente é a de saber como podemos comparar nossas idéias à realidade e assim conhecer a sua verdade (James apud Durkheim, 2004, p. 73).

O esforço de Durkheim de entender as teses pragmatistas sobre a experiência do sujeito como sendo o produto de certa liberdade e criatividade que rompe com a obrigação coletiva, não foi em vão. Pois encontramos esta ambivalência entre liberdade e obrigação como sendo uma categoria explicativa central para o entendimento da dádiva no modo como foi formulada por Mauss e seguidores. Esta observação nos leva a avançar no entendimento do simbolismo, que tem importância decisiva no desenvolvimento da escola de sociologia francesa entre Durkheim e Mauss.

No nosso entender, porém, o passo na direção de um diálogo mais amplo entre escolas não é dado por Durkheim, que faleceu precocemente. Este passo foi dado por Mauss, no momento em que ele sistematiza os estudos sobre a dádiva, o que permite articular dinamicamente o todo e a parte, o macro e o micro, o simbólico e o material ${ }^{9}$. A invenção do simbó-

\footnotetext{
${ }^{9}$ Durkheim, que faleceu antes de completar 60 anos, deprimido com a morte de vários auxiliares nos conflitos da Primeira Guerra Mundial, não completou sua obra. No entanto, esta herança da sua última fase foi resgatada por Mauss, que se encarregou de recolher as anota-
} 
lico, lembra C. Tarot, ocorre no interior da escola francesa, entre Durkheim e Mauss (Tarot, 1999), abrindo um campo de pesquisa importante entre os estudos sociais, culturais, linguísticos, políticos e econômicos. O valor do simbólico marca uma diferença importante do pensamento continental com relação à escola anglo-saxônica, a qual se funda numa abordagem empirista e causalista da realidade e pouco sensível ao mágico e ao ritual na organização das práticas humanas. Enquanto esta escola promove a racionalidade cognitiva como central na organização da ação individual e coletiva, a escola francesa busca articular esta racionalidade cognitiva com os símbolos, signos e imagens, na representação da prática social. E isto faz grande diferença, e não pode ser negligenciado pelos teóricos.

Por conseguinte, a dádiva atualiza a importância da escola francesa, abrindo uma nova compreensão da prática social entre pessoas morais e físicas, que é da maior atualidade para o entendimento das sociedades contemporâneas. A escola francesa, ao valorizar a moral e a estética na classificação social, tanto abriu temas originais (corpo, preces, ritos etc.) como avançou nos estudos das representações, das crenças e, logo, do simbólico da vida social, como vamos aprofundar a seguir.

\section{O fato social total e o simbólico}

\section{na passagem de Durkheim a Mauss}

Ao buscar na sua obra uma reinterpretação significativa das noções de "consciência coletiva" e de "representações", Durkheim deixou claro que a vida social só se torna possível graças a um vasto simbolismo. Os sentimentos coletivos podem igualmente encarnar-se em pessoas e fór-

$\overline{c ̧ o ̃ e s ~ d e ~ a u l a s ~ d e ~ e x-a l u n o s ~ p a r a ~ o r g a n i z a r ~ o ~ l i v r o ~ s o b r e ~ s o c i o l o g i a ~ e ~ p r a g m a t i s m o ~ j a ́ ~ a p r e c i a d o, ~}$ e que Mauss denominou como sendo a coroação da obra filosófica de Durkheim - embora a primeira edição póstuma desse curso, diga-se de passagem, apenas tenha sido realizada por Armand Cuvillier, em 1955. 
mulas: há fórmulas que são bandeiras; há personagens reais ou míticos que são símbolos (Durkheim, 1990, p. 314-315). Tanto Durkheim quanto Mauss nomearão de símbolos, inicialmente, aquilo que se designava como representações, embora Mauss amplie progressivamente a noção de simbólico, de modo a incluir nesta definição o próprio fato "material", superando a dualidade durkheimiana entre simbólico e material (Caillé, 1998). Na verdade, o clima do pré-guerra era de efervescência intelectual, propícia para novas sistematizações teóricas sobre o simbólico na ação social, a partir de estudos sociológicos, semiológicos e linguísticos, sendo o elemento religioso um pressuposto indispensável neste debate.

O símbolo como representação ajuda a explicar os sistemas religiosos como crenças coletivas com eficácia indiscutível na produção da realidade social. A religião é uma coisa eminentemente social. As representações religiosas são representações coletivas que exprimem realidades coletivas (Durkheim, 2009, p. VXI). Aqui, o fenômeno religioso ganha importância como fato social e aquilo que para Marx era o ópio do povo passa a ser, pelas mãos de Durkheim, um objeto histórico e sociológico importante e particular na organização da vida social. Por outro lado, o simbolismo como ação prática ajuda a compreender os rituais de doação como significantes do fato social. De fato, para Mauss, o valor das coisas não pode ser superior ao valor da relação entre as pessoas, sendo o simbolismo fundamental para a vida social (MARTINS, 2009). Mas, enquanto em Durkheim os símbolos ainda são pensados na ordem da representação, em Mauss, a noção de representação se dissolve nos signos em circulação nas práticas. Ao conceber o social como um simbolismo, Mauss descobriu uma forma para respeitar a realidade do indivíduo, a do social, e a variedade das culturas, afirma Caillé apoiado em Merleau-Ponty, sem torná-las impermeáveis uma à outra (Caillé, 2002, p. 223). 
O desenvolvimento teórico dos temas da magia e da religião por Durkheim e Mauss, foi um caminho importante para o entendimento do simbólico na vida social (Tarot, 1999). Com isso, eles conseguiram formular a relação entre crenças coletivas e a produção das práticas; e, em seguida, a experiência individual como produção de crenças. Porém, se em Durkheim, os símbolos como o totem permanecem como uma derivação externa da efervescência do grupo social, em Mauss, os símbolos, como é o caso do potlach, se inscrevem no interior das práticas sociais como elementos constitutivos destas. Durkheim e Mauss se deram, logo, as mãos na invenção do simbólico a partir de dois estágios: um, o simbólico aparece como representação; no outro, antecipado por Mauss nos estudos sobre a magia, mas amplificado com o dom, o simbólico se revela como ação prática ${ }^{10}$.

O entendimento do simbólico como estrutura de significação das relações sociais leva Mauss a criticar todo o reducionismo que atribui a um fenômeno isolado a origem substantiva da vida social, como é o caso do utilitarismo econômico na atualidade. Daí, a importância de Mauss para a crítica social e moral do capitalismo na contemporaneidade. Ao ser cativado pelos novos diálogos das fronteiras da psicologia e semiologia, por exemplo, Mauss superou a visão dualista do seu tio, para explorar de perto não apenas o que se representa, mas aquilo que se apresenta dinamicamente a cada momento pelos rituais, pelos gestos e pelos presentes solenemente dados e recebidos, com o lembra A. Caillé (1998). Nesse esforço de entender as razões não econômicas das trocas sociais, Mauss afastou-se progressivamente da abordagem positiva inicial de Durkheim

\footnotetext{
${ }^{10}$ No Esboço de uma teoria geral da magia, publicado na Année Sociologique, em 1904, Mauss e Hubert já afirmavam que a magia podia ser chamada de uma ideia prática, pois os atos e as representações eram inseparáveis (MAUSS, 2003: 126). E no texto Essai sur la nature et la function du sacrifice, em 1899, Mauss e Hubert, lembrando Tylor, dizem que o sacrifício é originariamente uma dádiva que o selvagem faz a seres naturais que Ihes convém se ligar, sendo os ritos sacrificais modalidades de iniciativas adotadas pelos indivíduos para fazer chegar aos deuses as coisas espiritualizadas (Mauss, 2005, p. 08).
} 
- a representação como estando separada da realidade - para introduzir o tema da mediação simbólica da totalidade, pela qual a representação está dentro da realidade, o que constitui um salto teórico que somente é completamente elucidado no diálogo entre Durkheim e Mauss.

Para Mauss, a lógica mercantil moderna não substitui as antigas formas de constituição dos vínculos e das alianças entre os seres humanos, e tais formas continuam presentes na sociedade moderna. A partir da análise do modo de circulação dos bens, serviços, poderes e pessoas, em certas culturas não europeias como aquelas da Polinésia, da Melanésia e do Noroeste norte-americano, o que configura também o caráter heterocêntrico de sua obra, Mauss assumiu progressivamente o pressuposto de que essas prestações seriam fatos sociais totais que envolviam obrigatoriamente todas as instituições de cada sociedade e as pessoas morais nelas presentes. Propôs que a troca primitiva englobaria a totalidade da sociedade em cada um dos atos que a compunha e que esta tese continuaria válida nos temos modernos. A ideia do fato social total permitiria, segundo ele, ligar o coletivo com o individual, o físico com o psíquico, o sagrado com o profano como partes de uma experiência integrada, pois:

Nestes fenómenos sociais 'totais', como propomos chamarIhes, exprimem-se ao mesmo tempo e de uma só vez todas as espécies de instituições: religiosas, jurídicas e morais - e estas políticas e familiares ao mesmo tempo; econômicas e estas supõem formas particulares da produção e do consumo, ou antes, da prestação e da distribuição; sem contar os fenômenos estéticos a que estes factos vão dar e os fenómenos morfológicos que manifestam estas instituições (Mauss, 2008, p. 55).

O fato social, caracterizado em Durkheim pela obrigação, tornou-se com Mauss um fato social total, um fenômeno simbólico. Ao aperfeiçoar a premissa durkheimiana de que os fatos sociais não são mais considerados coisas e, sim, símbolos, Mauss superou Durkheim, radicalizando a 
ideia de que a sociedade é uma totalidade ligada por símbolos. Para B. Karsenti, estudioso de Mauss, os símbolos são um operador de tradução que permitem que uma manifestação individual - um grito, um ritual, um gesto... - seja compartilhado significativamente pelo grupo do qual o indivíduo faz parte (Karsenty, 1994, p.87). Assim, o entendimento da sociedade como fato social total permitiu a Mauss superar as dualidades conceituais presentes no pensamento de seu tio, Émile, articulando de modo dialógico categorias dicotômicas, como o sagrado e o profano, o individual e o coletivo, normal e patológico, sem perder de vista a imbricação entre o utilitário e o simbólico, entre interesse e desinteresse (Caillé, 1998, p. 9). Por isso, na introdução do livro de C. Tarot (1999), A. Caillé propõe que a superação do pensamento causalista e positivista de Durkheim permitiu a Mauss elaborar um pensamento de tradução que o coloca em ressonância com autores como Weber e Simmel, pois a dádiva é eminentemente um símbolo de mediação (Caillé, 1999, p. 14).

Mas, aqui, repetindo o que foi dito a respeito da presença da escola sociológica francesa na organização da teoria social, o problema se reproduz: como encaixar a teoria da dádiva no debate teórico mais geral? Neste texto, estamos buscando responder a esta pergunta seguindo dois caminhos. Um deles é o de esclarecer o significado da dádiva na sociologia, localizando seu desenvolvimento no interior da escola francesa e no interior do debate entre Durkheim e Mauss. O outro é demonstrar a importância da dádiva para a revelação da função do simbólico na organização da vida social contemporânea que, no nosso entender, representa uma contribuição muito relevante para apreender a complexidade semiológica da ação social, para além das racionalidades cognitivas dos atores individuais envolvidos na trama social, que é a base da sociologia anglo-saxão.

Esee é o contexto, no nosso entender, onde se desenvolve a trama da dádiva como sistema teórico voltado para elucidar o valor simbólico das 
relações sociais. Este é o caminho, pois, que consideramos necessário para explicar que a teoria da dádiva não é um constructo excêntrico no desenvolvimento do debate da escola francesa, mas, ao contrário, o desdobramento previsível do modo como Durkheim e Mauss integram o tema das significações morais, estéticas e afetivas no interior das práticas culturais e sociais, neste momento de organização da sociologia, nos inícios do século XX. Para avançar nossa reflexão, precisamos, ainda, trazer alguns elementos sobre a relação entre dádiva, simbólico e sociologia, que é crucial para a dimensão de síntese da dádiva na superação dos pensamentos dicotômicos em Durkheim, em particular, e na teoria sociológica, em geral.

\section{Contribuições da dádiva para a sociologia}

Durante muitos anos, a dádiva foi apresentada como uma teoria curiosa revelada ao grande público por M. Mauss, em 1924, mas que, por razões diversas, não teria um lugar claro nas ciências sociais e muito menos na sociologia. No máximo, ela era vista como a contribuição relevante deste para o desenvolvimento da antropologia estrutural, o que é verdade, mas que não condiz com sua importância maior, como demonstramos neste texto, e que tem a ver com o lugar da dádiva no panteão da teoria sociológica. O fato é que esta impressão do dom como uma teoria menos interessante no campo sociológico contribui para se cometer uma injustiça histórica com uma das mais complexas doutrinas sobre a sociedade, a qual se revela por sua pertinência teórica na superação de esquemas dualistas - entre o indivíduo e a sociedade, entre o macro e o micro, entre o subjetivo e o objetivo ou entre agência e estrutura - e a favor de uma visão sintética e complexa da prática social. A revalorização da dádiva no interior das ciências sociais já vem sendo feita por diversos autores (Godbout e Caillè, 1998; Caillé, 2002; Chanial, 2008; Martins, 2008), mas um 
esforço adicional necessitava ser realizado, para reforçar sua presença no interior da escola francesa, que é um dos propósitos deste texto.

O lugar da dádiva no interior da escola francesa de sociologia pode ser observado desde alguns aspectos. Em primeiro lugar, é interessante notar que, para demonstrar a existência da dádiva como prestações obrigatórias, ele recorre à noção durkheimiana de força. Mauss se pergunta, já no início do livro, que força há na coisa dada que faz que o donatário a retribua? (Mauss, 2003, p. 188). E ele aventa algumas soluções intermediárias como a da moral contratual ligada ao direito costumeiro e as formas e ideias que sempre presidiram a troca. Mas estas explicações são insuficientes para Mauss, que propõe um método de comparação para se estudar as formas arcaicas do contrato que realce a doação como a própria força constituinte da relação social. Há no potlatch, diz, uma virtude que força as dádivas a circularem, a serem dadas e retribuídas (Mauss, op. cit., p. 251).

Em outra passagem, diz que nas economias e nos direitos antigos não se observam simples trocas de bens, de riquezas e de produtos. Trata-se de coletividades que se obrigam mutuamente, trocam e contratam; as pessoas presentes no contrato são pessoas morais que se enfrentam e se opõem, quer em grupos ou desafiando-se diretamente. O que elas trocam não são exclusivamente bens e riquezas, coisas úteis economicamente. São, antes de mais nada, festins, ritos, serviços militares, mulheres, crianças, danças, festas, feiras, do quais o mercado é apenas um dos momentos (...) (Mauss, 2008, p. 58). A ideia de força como obrigação coletiva realizada por pessoas morais, que podem ser comunidades ou indivíduos, afasta qualquer possibilidade de organização de um esquema teórico em que há uma estruturasistema, num lado, e indivíduos-agentes, no outro, como no pensamento anglo-saxão. Aqui a força é o próprio movimento sincrônico e dinâmico do coletivo social na sua abertura ao complexo institucional.

Nessa perspectiva, a dádiva presta uma segunda contribuição importante à escola francesa de sociologia, que é a de evitar a fragmentação 
disciplinar que ameaça a sobrevivência da sociologia nos dias atuais. Para aqueles autores, a sociologia é um campo de reflexão e atuação mais amplo, que envolve o conjunto de práticas sociais, materiais e simbólicas. Nesse sentido, a dádiva tem um valor teórico e prático inestimável para a renovação das ciências sociais e da sociologia, por se constituir num marco interpretativo que permite, simultaneamente, a crítica do caráter moral do capitalismo, e por desvendar a importância das culturas não europeias para a crítica ao ocidentalismo ${ }^{11}$. Atrás de tudo, há a força ou a complexidade do dom como sistema explicativo que desliza entre o macro e o micro, entre o objetivo e o subjetivo, entre o material e o simbólico, entre o eurocentrismo e o altercentrismo.

Para Mauss (2008), o fato social inclui todos os fenômenos humanos, tanto de natureza econômica quanto cultural, política e religiosa, na medida em que não há uma determinação substantiva última, como a economia, ou mesmo a efervescência ou qualquer outro dispositivo que fizesse a mediação entre o estado natural e o estado social. A doação é a força espontânea que produz o vínculo e sua eliminação produz a desorganização da aliança social. Para Mauss, era fundamental destacar, dentro da complexidade das motivações e modalidades de interações das pessoas envolvidas, o caráter voluntário, aparentemente livre e gratuito e, todavia, forçado e interessado dessas prestações. Para ele, o símbolo não é uma categoria isolada, mas algo que se realiza por seu uso nas diversas interações que se estabelecem com outros símbolos, o que explica a emergência do dom como um símbolo ou um sistema de significantes sincrônicos ${ }^{12}$.

\footnotetext{
${ }^{11}$ É importante assinalar que Mauss foi buscar em culturas não europeias as provas para a existência do dom como uma regra que é universal, mas cuja existência depende dos modos particulares de manifestação da prestação da doação em diferentes culturas.

${ }^{12}$ Esclarece Tarot que o simbolismo não constitui um território balizado, mas uma terra de exploração; trata-se de um continente a descobrir e a rememorar, algumas vezes uma terra a exumar, como o dom (Tarot apud Martins, 2006, p. 101).
} 
Uma terceira contribuição da dádiva para a sociologia contemporânea foi a de resgatar a relação entre cognição e expressividade, ou entre moral e estética. O entendimento da dádiva com expressão central do simbolismo social ${ }^{13}$ tem importância inegável para se repensarem os fundamentos morais e estéticos da modernidade e, em particular, para se avançar sobre o entendimento da natureza da sociedade e da relação entre cultura e natureza, temas que tanto intrigavam os fundadores da escola francesa de sociologia. O sistema da dádiva encontra inspiração nos desenvolvimentos paralelos e compartilhados de Durkheim e Mauss, na explicação da natureza complexa do fato social e na crítica a abordagens reducionistas sobre a vida social.

Também é de se registrar a importância do dom para se superar a dicotomia sociológica clássica entre objetivismo e subjetivismo ou representação e experiência. Nessa direção, os esforços empreendidos por Durkheim de articular o simbólico como representação derivada da realidade social, como vemos na valorização teórica do totem australiano em Formas elementares da vida religiosa, de 1912, e a preocupação de Mauss de entender o sacrifício como dádiva, no livro que escreveu com Hubert ainda em 1899 e intitulado "Essai sur la nature et la function du sacrifice", avançam nesta direção de aprofundamento da relação entre representação, realidade e experiência. Assim, podemos propor que a dádiva - que começa a ser pensada desde os textos de Mauss sobre magia e sacrifício, no início do século XX -, ganha corpo a partir dos avanços simultâneos que fazem Durkheim e Mauss a respeito dos temas do fato social e do simbólico, e entre um e outro, os temas do coletivo e do individual.

\footnotetext{
${ }^{13}$ Quando as categorias da ação humana se manifestam para a linguagem da vida e da morte, da guerra e da paz, estas serão instituídas em todas as atividades simbólicas desenvolvidas pela humanidade. O símbolo não é, portanto, com efeito, outra coisa originalmente a não ser o próprio sinal da aliança que deve perdurar além de toda separação ou afastamento; a comemoração sempre viva da aliança que o dom institui (Caillé, 2002, p. 103).
} 
Porém, uma das mais importantes contribuições da dádiva para a sociologia contemporânea é o fato de que ela se constitui na base de uma crítica importante ao utilitarismo econômico moderno, como já lembraram vários autores (Godbout, 1998, Cailllé, 1998 e 1992; Martins, 2008). Refutando a noção corrente de uma sociedade supostamente baseada na maximização de uma economia natural fundada nos interesses individuais, Mauss coloca em destaque o entrelaçamento entre fenômenos econômicos, morais, estéticos, religiosos e jurídicos no seio de prestações e contraprestações que se apresentam, preferencialmente, como atos voluntários, mas nos quais se entrevê a força obrigatória do dever (Mauss, 2008, p. 45). Essa passagem evidencia que, para Mauss, a antítese do dom não é o mercado, mas a ausência de relação e/ou vínculo. Assim, as interações sociais são movidas por razões que ultrapassam os interesses materiais e utilitários.

Finalmente, temos que ressaltar que, em Mauss, a dádiva não é uma lógica neutra, como foi apresentada posteriormente pelo estruturalismo levi-straussiano. Caillé (1992) tem chamado a atenção sobre a relação estreita entre dádiva e política e, nessa direção, arriscamos sugerir que a própria ideia de correr o risco de viver, de se relacionar com outrem já é uma ação política. É assim que entendemos a afirmação de Mauss, na conclusão geral do seu livro, quando, inspirado num provérbio maori, Mauss afirma que de uma ponta à outra da evolução humana não há duas sabedorias. Que adotemos então como princípio de nossa vida o que sempre foi um princípio e sempre o será: sair de si, dar, de maneira livre e obrigatória; não há risco de nos enganarmos (Mauss, op. cit., p. 301). Assim, a questão do simbólico em Mauss adquire um papel central na articulação do dom como política. Aqui, pode-se entender o valor dos gestos, palavras, rituais e imagens como dádivas, como ações necessárias à comunhão coletiva. Lembra Caillé que (...) aquilo que Hannah Arendt denomina ação, por exemplo, tem íntimo parentesco com o dom de $M$. 
Mauss (Caillé, 2002, p. 235). Assim, ao relacionar o dom com o símbolo, é possível interpretar o signo da aliança.

Caillé (2002) aponta três termos para pensarmos a interdependência complexa do paradigma do dom: o dom, o simbolismo e o político. Esses termos se distinguem das esferas das atividades regidas somente pelas coerções utilitaristas e funcionais, como vemos em Durkheim, para introduzir o paradoxo de ações movidas ao mesmo tempo pelo interesse e pelo desinteresse, pela liberdade e pela obrigação. Este paradoxo, para Mauss, se resolve quando se articulam as diversas áreas sociais com a política, nos levando então a associar a dádiva com a política - o que somente é permitido quando se compreende a sociedade na sua totalidade simbólica. Nesse momento, a dádiva também aparece não como uma política qualquer, mas a política da arte da vida, isto é, a política do fato social integral. É o que ele afirma nas suas últimas palavras do Ensaio sobre a dádiva e que reservamos para fechar esta seção:

Estudos deste gênero permitem, com efeito, entrever, medir, avaliar os diversos móveis estéticos, morais, religiosos, econômicos os diversos fatores materiais e demográficos cujo conjunto funda a sociedade e constitui a vida em comum e cuja direção consciente é a arte suprema, a Política, no sentido socrático da palavra (Mauss, 2003, p. 314).

\section{Alguns comentários finais}

Neste artigo, procuramos demonstrar que a sistematização da dádiva por Mauss não foi um fato aleatório, mas um projeto que se inscreve na própria tradição da escola francesa de sociologia e desde, pelo menos, o início do século XX. Esperamos ter respondido que a descoberta do simbólico somente poderia ter sido feita pelos autores franceses da escola francesa de sociologia, que pensavam a vida social desde categorias 
coletivas morais e estéticas, diferentemente dos autores anglo-saxônicos, prisioneiros de ideais empiristas e causalistas, sem espaço para a representação e a simbolização da totalidade social e da relação orgânica entre a parte e o todo. O simbólico foi um passo imprescindível para que a ideia de fato social, em Durkheim, se transformasse progressivamente em fato social total, em Mauss.

Em Mauss, a dádiva e o símbolo passam a ser coextensivos e reversíveis, o que levou C. Tarot a propor que o símbolo maussiano do símbolo não é a palavra ou o fonema, é a dádiva (Tarot, 1996). O simbólico constitui uma estrutura conceitual complexa, por permitir o entendimento dos significados, símbolos, imagens e instituições sociais não como partes compartimentadas do sistema social, mas como a unidade semântica do social. O simbólico aparece, na obra de Mauss, como um recurso fundamental para a crítica ao simplismo das doutrinas econômicas, observação que continua válida na contemporaneidade. Assim, sem negligenciar o valor dos fatores econômicos na organização da vida social, Mauss os submete e os dilui em determinações mais amplas de caráter cultural, religioso, moral, estético e político, que obedecem significações compartilhadas (Caillé, 2008, p. 31).

Para concluir esta reflexão, destacaremos cinco pontos que sintetizam o que foi aqui discutido. Em primeiro lugar, é importante lembrar que a passagem da ideia de fato social para o fato social total somente foi possível pela transformação do pensamento classificatório de Durkheim e Mauss num pensamento do simbólico, que reorganiza as categorias como uma estrutura significativa de práticas e bens em circulação como os valores, os dinheiros, os reconhecimentos. Nessa passagem, Mauss desvenda uma regra de base que rege as trocas sociais - o dar, o receber e o retribuir - que tanto libera como obriga as pessoas morais e físicas envolvidas. É nesta fissura que ele abre uma porta para o diálogo anglo-saxônico entre agência e estrutura - antes impossível de ser formulado desde Durkheim. 
Em segundo lugar, balizaremos que a passagem de uma ideia da sociedade como obrigação coletiva anterior à liberdade individual marca a fase inicial da escola francesa de sociologia. E o tema da liberdade de ação racional emerge como uma nova variável na organização das práticas e representações. Esses fatos tiveram impactos decisivos no desenvolvimento da sociologia continental. E, aqui, a decisão de Durkheim de dialogar com os pragmatistas norte-americanos foi particularmente relevante, por Ihe sugerir o contrato social como um sistema teórico paradoxal, no qual as motivações de representações e obrigações coletivas são testadas por racionalidades individuais movidas pelo valor da liberdade de decisão.

Em terceiro lugar, é interessante notar que a abertura do diálogo da sociologia francesa com outras disciplinas como a etnologia, a filosofia pragmática, a psicologia e a antropologia, foi fundamental para Durkheim e Mauss elaborarem uma teoria complexa do simbolismo, sem a qual não teria sido possível a Mauss sistematizar os estudos sobre a dádiva. O simbólico contribuiu para a superação entre uma abordagem que valoriza a ação pela escolha racional e outra que valoriza a ação pela escolha moral. Pelo simbolismo, decisões cognitivas e morais são submetidas a padrões de consciência coletivos abertos a significações individuais próprias de sociedades complexas e estratificadas.

Em quarto lugar, vale lembrar que Mauss conseguiu descompactar a ideia durkheimiana do fato social como expressão de uma efervescência social original, que é marcada pelo positivismo comtiano e pelas categorias aristotélicas da natureza humana, mediante a radicalização do entendimento do fato social como um fato da prática; do fato social como sendo material e simbólico; do fato social como sendo um fenômeno que articula a sociedade e o indivíduo, não por crenças ou cálculos anteriores às práticas, mas por motivos inscritos na própria prática. Por esta via, Mauss conseguiu introduzir a dádiva como valor, como mediador sim- 
bólico, que tem, sem dúvidas, grandes implicações para a crítica moral e política mais ampla da sociedade ocidental contemporânea.

Em quinto lugar, é importante destacar que o entendimento das naturezas diferenciadas das escolas sociológicas aqui lembradas - a francesa e a anglo-saxônica - abre um campo de discussão para se entender a variedade de escolas de pensamento social que continuam a guardar suas marcas particulares, apesar da globalização. E o reconhecimento desta pluralidade de escolas, que mantêm coerência com certas estruturas históricas e culturais, também valoriza a importância de se abrir o entendimento para a pluralidade de escolas e saberes que estão legitimando novas tendências do pensamento, como aqueles dos estudos feministas ou dos estudos pós-coloniais entre outros.

Paulo Henrique Martins. Professor Titular do Departamento de Sociologia da UFPE; Bolsista de Produtividade 1C do CNPq; Presidente da ALAS (Associação Latino-Americana de Sociologia); Vice-Presidente da Associação MAUSS (Mouvement Anti-Utilitariste dans les Sciences Sociales), Coordenador do NUCEM (Núcleo de Cidadania e Processos de Mudança) da UFPE.

$\measuredangle$ pahem@terra.com.br

Juliana de Farias Pessoa Guerra. Mestranda do Programa de Pós-Graduação de Sociologia da UFPE; Pesquisadora do NUCEM/UFPE; Assessora de comunicação do IMIP (Instituto de Medicina Infantil) de PE; Coordenadora do núcleo de comunicação e saúde da Faculdade Pernambucana de Saúde. 


\section{Referências}

ARISTOTLE. Categories. In: ARISTOTLE. Complete works. New Jersey: Princeton University Press, 1995.

ARISTÓTELES. Política. In: Aristóteles. Os pensadores. Editora Nova Cultural Ltda, 1999.

CAILLÉ, A. Nem holismo nem individualismo metodológicos. Revista Brasileira de Ciências Sociais, v.13, n.38, 1998.

CAILLÉ, A. Preface In TAROT, Camille. De Durkheim à Mauss, I'invention du symbolisme. Sociologie et sciences des religions. Paris : La Découverte/MAUSS, 1999.

CAILLÉ, A. O paradigma do dom: o terceiro paradigma. Petrópolis, RJ: Vozes, 2002.

CHANIAL, P. La société vue du Don. Manuel de sociologie anti-utilitariste appliquée. Paris : La Découverte, 2008.

COOLEY, C. On self and social organization. Chicago e Londres: The University of Chicago Press, 1998.

DEWEY, J. The public and its problems. Swallow Press/ Ohio University Press, 1991.

DURKHEIM, E. Leçons de sociologie. Paris: PUF, 1997.

DURKHEIM, E. Les formes élementaires de la vie religieuse. Paris: PUF/Quadrige, 1990.

DURKHEIM, E. As formas elementares da vida religiosa. São Paulo: Martins Fontes. 2009.

DURKHEIM, E. A divisão do trabalho social. São Paulo, SP: Martins Fontes, 2008.

DURKHEIM, E. Pragmatismo e sociologia. Florianópolis, SC: UFSC, 2004.

DURKHEIM, É., MAUSS, M. Algumas Formas Primitivas de Classificação (1903). In: MAUSS, M. Ensaios de Sociologia. São Paulo: Ed. Perspectiva, 1995.

GIDDENS, A. The constitution of society. California: The university of California Press, 1984.

GODBOUT, J. Introdução à Dádiva: Um privilégio paradigmático. Revista Brasileira de Ciências Sociais, n. 8, v. 13, ANPOCS, 1998.

GODBOUT, J.; CAILLÉ, A. O espírito da dádiva. Rio: FGV, 1998. 
JAMES, W. Pragmatism. Indianapolis/Cambridge: Hackett Publishing Company, 1981.

KARSENTI, B. Marcel Mauss. Le fait social total. Paris: PUF, 1987.

MALINOWSKI, B. Argonautas do pacifico ocidental: Um relato do empreendimento e da aventura dos nativos nos arquipélagos da Nova Guiné melanesia. São Paulo: Abril Cultural. 436 p. (Coleção Os Pensadores); v.43), 1976.

MAUSS, M. Sociologia e antropologia. São Paulo: Cosac \& Naify, 2003.

MAUSS, M. Ensaio sobre a dádiva. Lisboa: Edições 70, 2008.

MAUSS, M.; HUBERT, H. Esboço de uma teoria geral da magia In: MAUSS, M. Sociologia e antropologia. São Paulo: Cosac \& Naify, 2003.

MAUSS, M.; HUBERT, H. Sobre o sacrifício. São Paulo: Cosac \&Naify, 2005.

MARTINS, P. H.; CAMPOS, R. Polifonia do dom. Recife: Ed. Universitária da UFPE, 2006.

MARTINS, P. H. A dádiva entre os modernos: discussão sobre os fundamentos e as regras do social. Petrópolis, RJ: Vozes, 2009.

MARTINS, P. H. De Lévi-Strauss a M.A.U.S.S. - Movimento Antiutilitarista nas Ciências Sociais: Itinerários do Dom. Revista Brasileira de Ciências Sociais, Vol. 23 no. 66, fevereiro/2008.

MARTINS, P. H. A dádiva como mediação no cuidado em saúde: implicações para o direito. In: PINHEIRO, R.; SILVEIRA, R.; LOFEGO, J.; SILVA JÚNIOR, A. G. (Org.). Integralidade sem fronteiras: itinerários de justiça, formativos e de gestão na busca por cuidado. 1a ed.Rio de Janeiro: CEPESC-IMS-UERJ-ABRASCO, 2012.

SCHUTZ, A. The phenomenology of the social world. Northwestern University Press, 1967.

TAROT, C. Du fait social de Durkheim au fait social total de Mauss, un changement de paradigme? La Revue du MAUSS semestrielle, 8, 2 semestre, 1996.

TAROT, C. De Durkheim à Mauss, I'invention du symbolisme. Sociologie et sciences des religions. Paris : La Découverte/MAUSS, 1999.

Recebido em: 23/01/2013

Aceite final em: 10/04/2013 